\title{
A 62-year-old woman with syncope
}

\author{
Christine Soong MD MSc, Benjamin H. Chen MD, Brian M. Wong MD
}

Choosing Wisely Canada
Competing interests: Christine Soong reports receiving fees as an invited speaker at the 12th Annual Conference of the Canadian Society of Hospital

Medicine in 2014. Christine

Soong and Brian Wong are cochairs of the Canadian

Society of Internal

Medicine's Choosing

Wisely Canada committee.

No other competing

interests were declared.

This article has been peer reviewed.

Correspondence to:

Christine Soong,

christine.soong@utoronto.ca

CMAJ 2015. DOI:10.1503 /cmaj.141313
A 62-year-old woman living independently presents to the emergency department after briefly losing consciousness while straining on the toilet. The patient felt well shortly before and immediately after the event; no associated trauma or confusion occurred. The patient had experienced a similar episode of syncope six months earlier, which had been investigated with an echocardiogram with a normal result. She has a known history of stroke affecting the posterior circulation and receives appropriate secondary prevention treatment (acetylsalicylic acid [81 mg/d], perindopril [4 mg/d], and atorvastatin $[20 \mathrm{mg} / \mathrm{d}])$. An initial assessment of the patient's condition shows normal vital signs, no signs of volume depletion, and normal results on cardiovascular and neurologic examination.

\section{What diagnoses should be considered?}

Syncope is a common symptom, occurring in at least $30 \%$ of the adult population. ${ }^{1}$ The differential diagnoses in this patient's case include micturition and vasovagal syncope (neurally mediated mechanisms associated with autonomic impairment), arrhythmias, valvular disease, outflow obstruction and orthostatic hypotension. ${ }^{2,3}$ Neurologic causes of syncope, such as transient ischemic attack (TIA), stroke or seizure, are almost always associated with features suggestive of the underlying cause (e.g., asymmetric motor weakness, and deficits in speech, vision and sensation in TIA or stroke; aura, tonic posturing and postictal confusion in seizure) and account for less than $5 \%$ of all cases of syncope. ${ }^{1,4}$

\section{Are there any "red flags" on history or physical examination?}

The initial history and physical examination should focus on distinguishing relatively benign causes of syncope (e.g., reflex syncope, such as vasovagal or situational syncope; orthostatic hypotension) from high-risk causes (e.g., cardiac disorders). Features suggestive of benign causes include situational precipitants such as emotional stress or activity (e.g., micturition, defecation, coughing) with an associated prodrome (e.g., nausea, sweating or dizziness), or orthostatic hypotension. ${ }^{1,5}$ High-risk features, or "red flags," suggestive of a cardiac cause include syncope during exertion, palpitations at the time of syncope, evidence of cardiovascular disease or a family history of sudden cardiac death (Box 1).

What initial investigations are necessary? Guidelines from the American College of Emergency Physicians and from cardiovascular societies in Canada, the United States and Europe, support a structured approach to the evaluation of syncope. ${ }^{1,4-7}$ If a detailed history, physical examination and normal electrocardiography (ECG) suggest reflex or orthostatic syncope, further testing is usually not required.

Other cases of undiagnosed syncope are further stratified into low, intermediate and high cardiovascular risk using features on history and physical examination, with the latter two categories warranting further tests, such as echocardiography, rhythm monitoring (i.e., using Holter, event or loop recorders) and stress tests. ${ }^{1,5-7}$ Laboratory investigations may be considered if underlying causes, such as anemia, or metabolic disturbances, such as hypoglycemia or hypercapnia, are suspected. ${ }^{4,8,9}$ Further cardiac investigations or admission to hospital for observation should be guided by the presence of red flags (Box 1). ${ }^{1-3}$

\section{Should the patient undergo neuroimaging?}

If patients presenting with simple syncope have a normal neurologic examination, neuroimaging studies are not necessary. Observational studies involving patients presenting to the emergency department with syncope found the diagnostic yield of neuroimaging (computed tomography $[\mathrm{CT}]$ and magnetic resonance imaging $[\mathrm{MRI}]$ of the brain, and ultrasonography of the carotid artery) to be less than 5\%, with head CT and ultrasonography of the carotid causing a change in management in less than $2 \%$ of cases. ${ }^{10}$ These studies have led to recommendations from Choosing Wisely Canada (Box 2), which advise limited use of neuroimaging studies in the evaluation of simple syncope. ${ }^{11}$ 


\section{Case revisited}

Because this patient's presentation is most consistent with an uncomplicated episode of syncope without important risk factors or new neurologic deficits, the most likely cause is vasovagal syncope. A 12-lead ECG did not show any concerning features of arrhythmia or ischemia. In addition, the patient already had known cerebrovascular disease and was taking appropriate secondary prevention treatments. Neuroimaging studies at this juncture would be of low diagnostic yield, be unlikely to alter management and expose the patient to unnecessary radiation; therefore, none were pursued. Instead,

\section{Box 1: Red flags requiring further evaluation in patients with syncope ${ }^{1-6}$}

- History or sign of cardiovascular disease (i.e., severe aortic stenosis, outflow obstruction, heart failure, myocardial infarction)

- Syncope during exertion

- Lack of prodrome

- Palpitations at the time of syncope

- Family history of sudden cardiac death

- Risk factors on electrocardiography, such as: - Bifascicular, Mobitz I second-degree, or complete (third-degree) heart block

- ischemic changes (T-wave inversion, STdepression, Q waves)

- Brugada syndrome (right bundle branch block with ST-elevation in leads V1-V3

- Prolonged QT interval

- New neurologic deficits

- Seizure (aura, witnessed tonic-clonic activity with postictal state)

\section{Box 2: Choosing Wisely Canada}

\section{recommendation ${ }^{11}$}

Do not routinely obtain neuroimaging studies (computed tomography [CT], magnetic resonance imaging or ultrasonography of the carotid artery) in the evaluation of simple syncope in patients with a normal neurologic examination.

- Although a neurologic cause is uncommon in syncope, providers must consider one in any patient who presents with transient loss of consciousness. In the absence of signs or symptoms concerning for neurologic causes (such as, but not limited to, focal neurologic deficits), neuroimaging studies are of limited benefit. Despite a lack of evidence for the diagnostic utility of neuroimaging in patients presenting with true syncope, providers continue to use CT imaging of the brain. Inappropriate use of diagnostic imaging carries high costs and subjects patients to the risks of radiation exposure. physicians reassured the patient, and she was discharged from the emergency department with follow-up with her family physician the following week.

\section{References}

1. Moya A, Sutton R, Ammirati F, et al. Guidelines for the diagnosis and management of syncope (version 2009): The Task Force for the Diagnosis and Management of Syncope of the European Society of Cardiology (ESC). Eur Heart J 2009; 30:2631-71.

2. Quinn JV, Stiell IG, McDermott DA, et al. Derivation of the San Francisco Syncope Rule to predict patients with short-term serious outcomes. Ann Emerg Med 2004;43:224-32.

3. Grossman SA, Fischer C, Lipsitz LA, et al. Predicting adverse outcomes in syncope. J Emerg Med 2007;33:233-9.

4. Linzer M, Yang EH, Estes NA 3rd, et al. Diagnosing syncope. Part 1: Value of history, physical examination, and electrocardiography. Clinical Efficacy Assessment Project of the American College of Physicians. Ann Intern Med 1997;126:989-96.

5. Strickberger SA, Benson DW, Biaggioni I, et al. AHA/ACCF Scientific Statement on the Evaluation of Syncope: From the American Heart Association Councils on Clinical Cardiology, Cardiovascular Nursing, Cardiovascular Disease in the Young, and Stroke, and the Quality of Care and Outcomes Research Interdisciplinary Working Group; and the American College of Cardiology Foundation: In Collaboration With the Heart Rhythm Society: Endorsed by the American Autonomic Society. Circulation 2006;113:316-27.

6. Huff JS, et al. Clinical policy: critical issues in the evaluation and management of adult patients presenting to the emergency department with syncope. Ann Emerg Med 2007;49:431-44.

7. Sheldon RS, Decker WW, Quinn JV, et al. Standardized approaches to the investigation of syncope: Canadian Cardiovascular Society position paper. Can J Cardiol 2011;27:246-53.

8. Eagle KA, Black HR. The impact of diagnostic tests in evaluating patients with syncope. Yale J Biol Med 1983;56:1-8.

9. Kapoor WN, Karpf M, Wieand S, et al. A prospective evaluation and follow-up of patients with syncope. $N$ Engl J Med 1983:309:197-204.

10. Mendu ML, McAvay G, Lampert R, et al. Yield of diagnostic tests in evaluating syncopal episodes in older patients. Arch Intern Med 2009;169:1299-305.

11. Canadian Society of Internal Medicine: five things physicians and patients should question. Toronto: Choosing Wisely Canada; 2014. Available: www.choosingwiselycanada.org/recommendations /canadian-society-of-internal-medicine/ (accessed 2014 Nov. 10).

Affiliations: Department of Medicine (Soong, Wong), University of Toronto; Division of General Internal Medicine (Soong), Mount Sinai Hospital, Toronto, Ont.; Department of Medicine (Chen), Queen's University, Kingston, Ont.; Lennox \& Addington County General Hospital (Chen), Napanee, Ont.; Division of General Internal Medicine (Wong), Sunnybrook Health Sciences Centre; Centre for Quality Improvement and Patient Safety (Wong), University of Toronto, Toronto, Ont.; Canadian Society of Internal Medicine (Soong, Chen, Wong), Ottawa, Ont.

Contributors: All of the authors contributed substantially to the conception and design of the article; to the acquisition, analysis and interpretation of data; and to writing or revising the article for important intellectual content. All of the authors approved the final version to be published and agreed to act as guarantor of the work.

Acknowledgement: The authors thank Dr. Neil Gibson for his comments on drafts of this report.

CMAJ is collaborating with Choosing Wisely Canada (www.choosingwiselycanada.org), with support from Health Canada, to publish a series of articles describing how to apply the Choosing Wisely Canada recommendations in clinical practice. 